\title{
Papéis Sociais e Envelhecimento em uma Perspectiva de Curso de Vida ${ }^{1}$
}

\author{
Iolete Ribeiro da Silva ${ }^{2}$ \\ Fundação Educacional do Distrito Federal \\ Isolda de Araújo Günther \\ Universidade de Brasília
}

\begin{abstract}
RESUMO - Este trabalho investigou os papéis sociais e as tarefas evolutivas desempenhados por adultos. O local escolhido para investigação foi um assentamento de famílias de baixa renda do Distrito Federal criado em 1989. Utilizou-se um questionário contendo 17 questões abertas e 15 questões fechadas, preenchido pela primeira autora durante uma visita domiciliar. Participaram 98 respondentes $(73 \mathrm{~F}$ e $25 \mathrm{M})$, sendo 51 entre 50 e 59 anos e 47 a partir de 60 anos. Os resultados apontaram que este grupo é heterogêneo e que seus papéis sociais são influenciados pelas variáveis demográficas (idade, sexo, escolaridade, ocupação, naturalidade e estado civil) e também pelas variáveis relativas à moradia atual. Concluiu-se também que as expectativas sociais, o suporte social e a escolarização são fatores de suma importância para oferecer recursos para a otimização e compensação necessárias a um envelhecimento bem sucedido.
\end{abstract}

Palavras-chave: papéis sociais; desenvolvimento adulto; envelhecimento; tarefas evolutivas.

\section{Social Roles and Aging From a Life-Span Perspective}

\begin{abstract}
This study investigated the social roles and developmental tasks of adults. The study took place in a settlement of low-income families, created in The Federal District in 1989. Data were collected through a questionnaire composed of 17 open and 15 closed questions, administered by the first author during a home visit. There were 98 respondents, 73 female and 25 male, being 51 between 50 to 59 years old and 47 elders above the age of 60 . The result indicated that this group is heterogeneous and that its social roles are influenced by the demographic variables - age, sex, educational level, work, place of the birth and marital status, as well for the relative variables to current residence. The data allow the conclusion that social expectations, social support and the educational level are important resources for the optimization and necessary compensation to successful aging.
\end{abstract}

Key words: social roles; adult development; aging; developmental tasks.

A compreensão do desenvolvimento adulto e do envelhecimento demanda esforços concentrados, se desejarmos identificar as mudanças e as transformações vivenciadas por esta faixa etária e possibilitar, assim, a ampliação da capacidade de planejamento de políticas públicas de atenção ao idoso (Anzola-Perez, 1985). Nesse contexto, espera-se que a psicologia forneça informações sobre o curso, as condições e as variações da vida adulta, bem como sobre os indicadores de uma velhice bem sucedida (Baltes, 1995).

Embora psicólogos venham realizando estudos sobre o envelhecimento há algum tempo, a área esteve mais voltada para a infância, como consequiência do predomínio da idéia de que a vida adulta constitui um período de estabilidade (Neri, 1995; Stevens-Long, 1979).

1 Este estudo fundamenta-se na dissertação de mestrado da primeira autora, defendida no Instituto de Psicologia, UnB, em maio de 1998, sob orientação da segunda autora. $\mathrm{O}$ trabalho contou com o apoio do $\mathrm{CNPq}$ em forma de bolsa para a primeira autora.

2 Endereço: Quadra 09, Conjunto A Casa 11, Sobradinho, DF; CEP: 73.035-091. E-mail: iolete@zaz.com.br.
Grande parte dos estudos sobre o desenvolvimento adulto tem-se apoiado na perspectiva teórica do desenvolvimento de curso de vida, proposta por Baltes, Reese e Lipsitt (1980). Esta abordagem difere da psicologia clássica do desenvolvimento, que supõe o término do desenvolvimento com o findar da adolescência. Sendo o desenvolvimento um processo multidirecional e multifuncional, influenciado pelo contexto histórico, abrangendo todo o curso de vida, ocorre um constante equilíbrio entre ganhos e perdas, que resulta numa variabilidade intra-individual e em plasticidade individual (Baltes, 1987).

À procura de um modelo teórico de envelhecimento bem sucedido, Baltes (1991) sugere que: (1) o curso do desenvolvimento apresenta variabilidade individual; (2) existem diferenças importantes entre envelhecimento normal, ótimo e patológico; (3) durante o envelhecimento fica resguardado o potencial de desenvolvimento; (4) os prejuízos deste período podem ser minimizados pela ativação das capacidades de reserva para o desenvolvimento; (5) as perdas cognitivas podem ser compensadas por ganhos no domínio da inteligência prática; (6) com o envelhecimento, o equilíbrio entre ganhos e perdas torna-se menos positivo; 


\section{R. Silva e I. A. Günther}

(7) os mecanismos de auto-regulação da personalidade mantêm-se intactos em idade avançada.

O envelhecimento bem sucedido é visto como um processo geral de adaptação descrito como otimização seletiva com compensação (Baltes, 1991). Depreende-se, então, que com a crescente limitação imposta pela natureza biológica e no intuito de aumentar suas potencialidades, a tarefa adaptativa do idoso consiste em selecionar metas e objetivos mais importantes, otimizar recursos e compensar perdas. Na tentativa de compreender como se dá esse processo de adaptação e ajustamento ao envelhecimento, em termos de recursos, limites e demandas sociais, foi desenvolvido este estudo sobre os papéis sociais na perspectiva do desenvolvimento adulto.

\section{Desenvolvimento adulto - tarefas evolutivas e papéis sociais}

O crescimento da população idosa é um fenômeno mundial. No Brasil, devido às inúmeras discrepâncias e profundas desigualdades regionais, o envelhecimento é heterogêneo, sendo afetado por características de migração, mortalidade, condições de vida, gênero, escolaridade e estado civil (Berquó, 1996).

Objetivando proteger esse crescente número de idosos, diversas leis têm sido aprovadas. Na realidade, tais leis confirmam a manutenção da imagem do bom velhinho, tranquiilo e tolerante. De fato, os idosos continuam despojados de autoridade real vez que "... a velhice não pode ser reduzida ao universo da proteção social... " (Haddad, 1993, p. 13) e, em vez de pretensos privilégios especiais, os idosos deveriam ter condições para viver dignamente.

Em relação às mudanças biológicas, ainda não possuímos respostas a todas as indagações de como e por que envelhecemos. As pesquisas têm demonstrado, entretanto, que as mudanças biológicas não devem ser encaradas como doenças. Hábitos de vida, condições de moradia, emprego e saúde interferem na qualidade de vida e geram um perfil diferenciado de envelhecimento. A motivação, a educação e a cultura favorecem os processos cognitivos, motores, sensoriais e intelectuais. Ocorre, também, a diminuição do potencial biológico e o aumento da necessidade de utilização dos recursos psicológicos, sociais e materiais oferecidos pela cultura, para compensar tais perdas (Baltes, 1997).

Embora o envelhecimento seja acompanhado de uma série de adversidades, a pior delas é o despojamento social. Ser idoso, na nossa sociedade é sobreviver sem projeto e se submeter às burocracias das instituições. É preciso que o indivíduo tenha projetos que não envelheçam, é preciso sedimentar uma cultura positiva da velhice "com interesses, trabalhos, responsabilidades que tornem sua sobrevivência digna" (Bosi, 1994, p. 81).

Neste sentido, a teoria de curso de vida enfatiza a importância da seleção de prioridades de vida para uma regulação efetiva dos processos desenvolvimentais. Essas prioridades e os investimentos pessoais não são arbitrários, pois envolvem concepções subjetivas de curso de vida e refletem tarefas evolutivas que as pessoas desempenham (Baltes, 1998). Segundo Neri (1991), as preferências individuais, as expectativas quanto ao futuro, as realizações e as metas são indicativas das tarefas evolutivas.

Havighurst (1953) afirma que o indivíduo deve desempenhar certas tarefas evolutivas, para se desenvolver adequadamente. Tais tarefas são enfrentadas de maneira diferente, devido aos diferentes valores, maturação física, expectativas sociais, oportunidades, preferências, competências e recursos (Baltes \& Silveberg, 1995).

Recorrendo à teoria de Erikson (1950), encontram-se dois conceitos: a) geratividade como tarefa evolutiva de adultos; b) integridade do ego como tarefa evolutiva específica de idosos. Geratividade significa contribuir para gerações futuras por meio da produção não só de aspectos materiais, mas também do cuidado e da manutenção de outros seres. Integridade do ego é a adaptação a triunfos e desilusões inerentes à condição de criador de outros seres humanos e gerador de produtos e idéias. É ter, em suma, dignidade, sabedoria, aceitação do modo de vida, senso de completude e unidade.

Para alcançar a integridade do "ego" é importante que o idoso possa fazer uma revisão de sua vida para dar-lhe sentido e reorganizar criativa e positivamente sua personalidade (Stevens-Long, 1979). Neste sentido, as tarefas evolutivas da velhice são formas de organização da vida que possibilitam até a aceitação da morte (Fitch, 1985). Um ambiente agressivo, assuntos familiares não resolvidos, ausência de cuidadores adequados podem dificultar este processo.

Segundo Lazaeta (1994), durante o envelhecimento, os principais fatores de influência da sociedade sobre o indivíduo são a resposta social ao declínio biológico, o afastamento do trabalho, a mudança da identidade social, a desvalorização social da velhice e a falta de definição sociocultural de atividades em que o idoso possa perceber-se útil e alcançar reconhecimento social. A vida do idoso é, portanto, dominada por um alto nível de estresse, devido às expectativas e obrigações formalizadas.

Nesse contexto Kahn e Antonucci (1979) ressaltam a importância das atividades que são esperadas de uma pessoa para entender as mudanças que ocorrem no curso de vida, vez que estão ocupando determinada posição no espaço social. Essas posições, definidas como papéis sociais, são influenciadas pelo que se espera de uma pessoa e pelo que a própria pessoa espera de si mesma. Tais papéis sociais apresentam propriedades positivas ao favorecerem oportunidades de aquisição e uso de habilidades. Apresentam propriedades negativas ao gerarem tensões, conflitos e ambigüidades.

Embora uma pessoa possa ocupar diversos papéis ao longo do curso de vida, alguns papéis estão explicitamente relacionados à idade, principalmente quanto à hierarquia. Os papéis também provêem oportunidade de acesso a lugares, pessoas e atividades. Dessa forma, a experiência do envelhecimento envolve necessariamente mudança de papéis (Kahn \& Antonucci, 1979).

Se não há uma adaptação ajustada às demandas, o envelhecimento pode ser vivenciado com alto nível de estresse, 
dificultando a realização das tarefas evolutivas. Por isso deve-se aprender a construir os principais papéis de vida com bastante flexibilidade, de forma que eles sejam compatíveis com a etapa de vida. Isso requer conhecimento mais profundo dos papéis sociais e suas propriedades, especialmente as positivas (Kahn \& Antonucci, 1979).

\section{Objetivos}

Considerando que o processo de envelhecimento gera uma agenda de desenvolvimento individual, que inclui a delimitação de papéis esperados pela sociedade (Neri, 1995), o propósito deste trabalho foi estudar os papéis sociais desempenhados por adultos a partir de 50 anos, com o objetivo de: (1) identificar as tarefas evolutivas desempenhadas pelos respondentes deste estudo; (2) conhecer os papéis sociais por eles exercidos; (3) investigar possíveis relações entre as variáveis demográficas, tarefas evolutivas e papéis sociais.

As variáveis foram organizadas em três grupos: (1) variáveis demográficas (sexo, idade, naturalidade, escolaridade, estado civil e ocupação); (2) variáveis ligadas às tarefas evolutivas; (3) variáveis ligadas aos papéis sociais.

Para identificar as tarefas evolutivas, foram estabelecidos dois subgrupos de variáveis: (1) relativas ao envelhecimento: sinais, autopercepção do envelhecimento, percepção de como as outras pessoas vêem os idosos; (2) relativas ao projeto de vida: o que mais gostou de haver realizado na vida, a preocupação principal no momento, como vive o seu dia e como imagina o futuro.

Para conhecer os papéis sociais dos respondentes, estabeleceram-se seis subgrupos de variáveis: (1) procedência: onde morava, lembranças do local onde morava; (2) moradia atual: tempo de moradia, motivos da mudança, o que mais agrada, o que menos agrada; (3) saúde: enfermidades e cuidados com a saúde; (4) arranjos de moradia: pessoas com as quais mora, tamanho da família; (5) atividades: atividades sociais, atividade que gosta e que não gosta de desenvolver; (6) rede de suporte: amigos, quem proporciona ajuda, tipos de ajuda que solicita, a quem ajuda e o tipo de ajuda que oferece.

\section{Metodologia}

O local escolhido para investigação foi um assentamento de famílias de baixa renda, criado em 1989 para atender a residentes em invasões. A seleção dos participantes foi aleatória, com a escolha de doze endereços por quadra, obedecendo aos seguintes critérios: (a) ter 50 anos ou mais; (b) residir na área escolhida para investigação. Sem o conhecimento de que casas possuíam pessoas na faixa etária desejada, todos os endereços sorteados foram visitados.

Este estudo foi conduzido com um grupo de 98 respondentes, sendo 51 adultos (50 a 59 anos), 29 idososjovens (60 a 69) e 18 idosos-idosos (70 anos ou mais). O critério "idade" foi definido em decorrência da decisão de

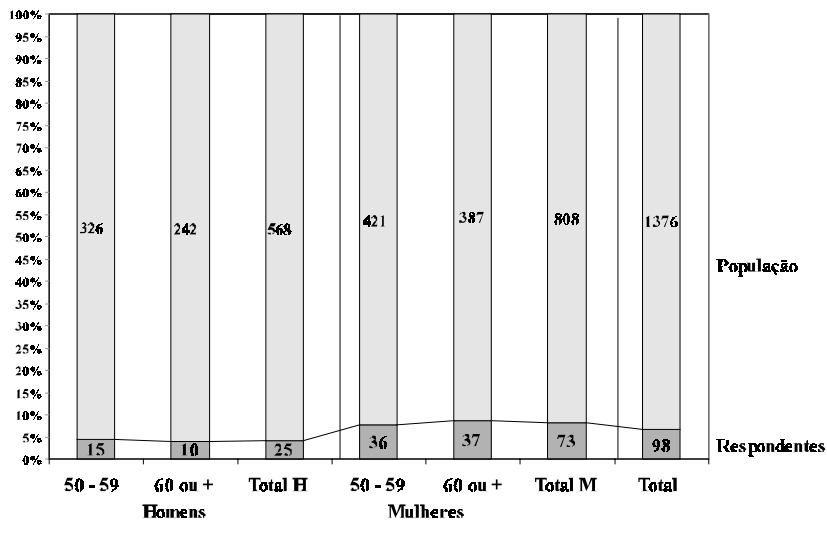

Figura 1 - Composição da Amostra - Dados sobre a população de Sobradinho II fornecidos pelo Programa Saúde em Casa de Sobradinho

se estudar os papéis sociais numa perspectiva do desenvolvimento adulto e tendo como ponto de partida as classificações adotadas por Baltes (1997), Neugarten e Weinstein (1964) e Veras (1994).

A figura 1 apresenta a composição da amostra em relação à população. A amostra representa $7,1 \%$ da população de 50 anos ou mais, $9 \%$ das mulheres e $4,4 \%$ dos homens, considerando como a população total, as $17.821(92,6 \%)$ pessoas cadastradas por um programa de saúde oferecido nas residências dos pacientes.

Para a coleta dos dados utilizou-se um questionário com 17 questões abertas e 15 questões fechadas, com o objetivo de coletar informações sobre sexo, idade, naturalidade, estado civil, procedência, moradia atual, escolaridade, atividade profissional, saúde, arranjos de moradia, rede de suporte social, sinais e percepção de envelhecimento, atividades e projeto de vida. Os participantes foram entrevistados em suas residências, em uma única sessão. A média de duração das entrevistas foi de 55 minutos.

A construção deste questionário teve como base algumas recomendações de Veras (1994) sobre a utilização de um questionário multidimensional. Em primeiro lugar aponta a vantagem da quantidade e precisão das informações que podem ser coletadas. Em segundo lugar recomenda o uso do método da entrevista cara a cara, porque permite estabelecer uma relação entre o respondente e o entrevistador, essencial para o alcance de um bom resultado.

Para testar esse questionário foram realizadas 08 (oito) entrevistas com participantes de um grupo de idosos em Sobradinho II, verificando a adequação das perguntas. Esses questionários não foram incorporados à amostra da pesquisa, servindo apenas para testar o instrumento.

Utilizaram-se medidas de tendência central e análise de correlações de Pearson, para avaliação dos dados. Todas as variáveis foram dicotômicas, classificadas em duas categorias: caso e não-caso ou sim e não. A análise de dados foi realizada com o pacote estatístico SPSS for Windows, na versão 7.5 . 


\section{R. Silva e I. A. Günther}

\section{Resultados}

De acordo com Tabela 1, a amostra compôs-se predominantemente de mulheres $(n=73)$, casados $(n=49)$, nãoalfabetizados $(n=40)$, com idade média de 61 anos $(D P=$ 9,74). Quanto ao local de nascimento, mais da metade da amostra é natural da região nordeste $(n=78)$. A maioria dos respondentes não está trabalhando $(n=65)$, e destes, apenas oito estão aposentados.

\section{Variáveis relacionadas às tarefas evolutivas}

Os sinais do envelhecimento mais apontados pelos respondentes foram as enfermidades $(n=60)$. A maioria $(n$ $=78$ ) considera que está envelhecendo e que as pessoas tem uma visão negativa da velhice $(n=57)$, associada à indiferença, preconceito e desprezo. Em relação ao projeto de vida a maioria dos respondentes informou que a realização de vida mais importante foi a família $(n=48)$, a principal preocupação do momento é com a família $(n=53)$, que no seu dia a dia vive bem $(n=34)$ e no futuro esperam estar satisfeitos em relação à vida pessoal, financeira e familiar $(n=75)$.

\section{Variáveis relacionadas aos papéis sociais}

Em relação à procedência, mais da metade $(n=60)$ dos respondentes moravam no estado quando da transferência para o local da pesquisa. Os respondentes vieram morar na residência atual porque ganharam o lote $(n=73)$; os fatores que mais lhe agradam na moradia atual são transporte, emprego e serviços de saúde $(n=41)$; o que mais desagrada é a falta de infra-estrutura básica $(n=43)$. As doenças mais referidas pelos respondentes foram as do aparelho circulatório $(n=43)$. No que se refere aos arranjos de moradia, predomi-

Tabela 1 - Distribuição dos respondentes segundo as variáveis demográficas $(n=98)$

\begin{tabular}{llr}
\hline & \multicolumn{1}{c}{ Variável } & N \\
\hline \multirow{2}{*}{ Sexo } & Feminino & 73 \\
& M asculino & 25 \\
\hline \multirow{3}{*}{ Estado Civil } & Casado & 49 \\
& Separado & 11 \\
& Solteiro & 17 \\
& Viúvo & 21 \\
\hline \multirow{3}{*}{ Escolaridade } & Não-alfabetizado & 44 \\
& Primário & 38 \\
Trabalho & Ginásio e Colegial & 16 \\
\hline \multirow{2}{*}{ N aturalidade } & Não trabalha & 65 \\
& Trabalha & 33 \\
\hline \multirow{2}{*}{ Faixa etária } & N ordeste & 78 \\
& C entro-0 este & 12 \\
& Sudeste & 8 \\
\hline
\end{tabular}

na a moradia com a família nuclear $(n=65)$. Quanto às atividades sociais, as religiosas $(n=61)$ são as mais freqüentadas. As atividades de que mais gostam são lavar a roupa, arrumar a casa e cozinhar $(n=35)$. Grande parte dos respondentes informou que tem amigos $(n=84)$, conversam mais com amigos e vizinhos $(n=67)$, ajudam outras pessoas $(n=50)$ e é ajudado $(n=76)$ por outras pessoas.

\section{Relações entre variáveis demográficas, tarefas evolutivas e papéis sociais.}

\section{Tarefas Evolutivas.}

Foram encontradas correlações significativas entre os sinais de envelhecimento, indicando que: (a) à medida que a idade aumenta, diminui a referência às mudanças na aparência como sinal de envelhecimento ( $r=-0,330)$; (b) as pessoas que trabalham se referem mais às enfermidades como sinal de envelhecimento $(r=0,212)$; (c) a referência aos sinais psicossociais negativos é menor entre os que trabalham ( $r=-0,280)$ e maior entre os separados $(r=0,206)$.

Em relação à percepção de como as pessoas da área em que habitam vêem o idoso, foram encontradas correlações significativas, indicando que entre os que freqüentaram a escola $(r=0,306)$, os que moram sozinhos $(r=0,253)$ e os que apontaram os sinais psicossociais negativos do envelhecimento ( $r=0,308$ ) há mais respondentes que se referem à visão negativa da velhice. Os respondentes casados $(r=0,233)$ e os que não estudaram $(r=-0,254)$ demonstraram uma visão neutra da velhice.

Em relação ao que mais gostou de haver realizado na vida, foram encontradas correlações significativas indicando que as pessoas que têm mais idade $(r=0,207)$ e apontaram a enfermidade como sinal de envelhecimento $(r=$ $0,236)$ se referiram mais à realização familiar. As referências à realização material são maiores entre os adultos $(r=$ $-0,221)$ e os que não apontaram que a comunidade apresenta uma visão negativa da velhice $(r=-0,221)$. A referência à realização profissional é maior entre os solteiros $(r=$ 0,262).

Quanto às preocupações atuais, as correlações indicaram que a preocupação com a saúde é maior entre os mais idosos $(r=0,206)$, entre os que não trabalham $(r=-0,240)$ e entre os que estão solteiros $(r=0,316)$. A preocupação com a situação financeira é maior entre os adultos $(r=-$ $0,253)$ e entre os que apontaram estar realizados profissionalmente $(r=0,203)$. Os que se preocupam mais com segurança, dependência e morte se sentem realizados em relação à família $(r=0,227)$.

Em relação a como vivem o cotidiano, as correlações significativas indicaram que: (a) os homens cuidam menos de casa e da família ( $r=-0,249)$; (b) os respondentes que freqüentaram a escola $(r=0,248)$, os adultos $(r=0,223)$, os que apontaram as mudanças na aparência como sinal do envelhecimento $(r=0,216)$, os que apontaram preocupação com a situação financeira $(r=0,200)$ e os que não se referiram à realização familiar $(r=-0,250)$ passam o dia 
trabalhando; (c) mais homens que mulheres informaram que passam o dia bem $(r=0,355)$.

A expectativa de que o futuro está nas mãos de Deus apresentou correlação significativa com preocupação financeira $(r=0,292)$ e com passar o dia trabalhando $(r=0,247)$.

\section{Papéis Sociais.}

A análise das variáveis demográficas indicou que: (a) mais homens trabalham $(r=0,276)$, mais homens estão casados $(r=0,304)$ e menos homens estão viúvos $(r=-0,306)$; (b) à medida que a idade aumenta, diminui o número de pessoas que freqüentaram a escola $(r=-0,323)$; (c) menos viúvos trabalham $(r=-0,214)$; (d) à medida que a idade aumenta, diminui o número de pessoas que trabalham $(r=-0,294)$.

Em relação a procedência, foi encontrada correlação significativa indicando que entre os que moravam no local da pesquisa havia maior número de pessoas que freqüentaram a escola $(r=0,234)$ e menos pessoas que se referiram à realização pessoal $(r=-0,222)$.

Em relação à moradia atual, foram encontradas correlações significativas indicando que: (a) quanto maior a idade, menor o tempo de residência $(r=-0,246)$; (b) as pessoas que moram há mais tempo no local informaram passar o dia trabalhando $(r=0,292)$.

Dentre os motivos de mudança para a atual moradia encontrou-se correlação significativa indicando que as pessoas que vieram ficar com a família têm mais idade $(r=0,292)$, não frequientaram a escola $(r=-0,263)$, vieram de outros estados $(r=-0,339)$, indicaram sentir-se realizados em relação à família $(r=0,275)$ e referiram não passar o dia bem $(r=-0,248)$. Foi encontrada correlação significativa indicando que as pessoas que se mudaram porque ganharam lote, têm menos idade $(r=-0,275)$, freqüentaram a escola $(r=0,315)$, já moravam no local onde se realizou a pesquisa $(r=0,436)$ e indicaram sentir-se realizados em relação aos bens materiais que conseguiram adquirir $(r=0,262)$.

Em relação à saúde, observou-se que a maioria dos respondentes que referem problemas são do sexo masculino $(r=-0,229)$. Entre os que apresentam problemas de saúde encontramos mais pessoas que afirmaram estar envelhecendo $(r=0,227)$, menos pessoas que se referiram à realização profissional $(r=-0,203)$ e menos pessoas que já moravam no local da pesquisa $(r=-0,205)$.

Em relação aos arranjos de moradia foram encontradas correlações significativas indicando que: (a) a maioria de mulheres $(r=-0,410)$, viúvos $(r=0,406)$, separados $(r=$ $0,379)$, e pessoas que se queixaram de doenças do aparelho circulatório $(r=0,239)$ moram com filhos e netos; (b) a maioria das pessoas que mora com o cônjuge e outros familiares são homens $(r=0,413)$, trabalham $(r=0,268)$ e se preocupam mais com a situação financeira $(r=0,218)$; (c) os respondentes que moram sozinhos são geralmente solteiros $(r=0,366)$, indicaram sentimento de realização profissional $(r=0,230)$, referiram uma visão negativa da velhice $(r=0,253)$, preocupação com a saúde $(r=0,325) \mathrm{e}$ gostam de atividades de lazer $(r=0,219)$.
Quanto às atividades sociais das quais participam, a análise das correlações indicaram que à medida que a idade aumenta $(r=0,207)$, aumenta a participação em atividades sociais, e que a atividade social predominante é a atividade religiosa $(r=0,751)$. Entre os respondentes que participam de atividades sociais encontramos mais pessoas que mudaram para ficar com a família $(r=0,208)$, que não se referiram a mudanças na aparência como sinal do envelhecimento $(r=-0,215)$ e que vivem esperando o dia passar $(r=-0,296)$. A análise da variável atividade religiosa indicou que: (a) as mulheres $(r=-0,220)$ e os mais idosos $(r=0,221)$ participam mais de atividades religiosas; (b) as pessoas que participam de atividades religiosas apontaram as enfermidades como sinal de que as pessoas estão envelhecendo $(r=0,207)$ e não se referiram a viver esperando o dia passar $(r=-0,284)$.

A análise das variáveis ligadas às atividades que os respondentes mais gostam de desenvolver indicaram que: (a) mais mulheres $(r=-0,252)$ e mais viúvas $(r=0,221)$ referem gostar de atividades domésticas; (b) os respondentes casados $(r=0,231)$ e os que não se referiram aos problemas de saúde $(r=-0,283)$ gostam mais de trabalhar; (c) as pessoas que indicaram conformar-se com tudo, são idosasidosas $(r=0,219)$, não freqüentaram a escola $(r=-0,250)$, preocupam-se mais com a saúde $(r=0,293)$, vieram para o local para ficar com a família $(r=0,408)$ e imaginam que, no futuro, poderão alcançar satisfação em relação à vida pessoal, familiar e financeira $(r=0,226)$.

Dentre as atividades que menos gostam de desenvolver, os adultos apontaram que não gostam das atividades domésticas $(r=-0,267)$. A variável não gostar de depender dos outros apresentou correlação significativa com escolaridade $(r=0,214)$, com sinais psicossociais negativos do envelhecimento $(r=0,334)$ e com visão negativa da velhice $(r=0,224)$.

A análise da variável ter amigos indicou que os viúvos possuem mais amigos $(r=0,213)$ e que as pessoas que mais se preocupam com a família têm menos amigos ( $r=$ $0,242)$. Os respondentes que indicaram que quando precisam conversar contam com amigos e vizinhos se referiram mais a estarem ansiosos em relação ao futuro, preocupando-se com doenças, dependência e morte $(r=0,223)$. Os respondentes que informaram contar com a família para conversar indicaram que não são ajudados por outras pessoas $(r=-0,229)$, referiram-se mais a viver cuidando de casa e da família $(r=0,205)$ e não se referiram à realização profissional $(r=-0,234)$.

Em relação ao suporte social observou-se que as pessoas que mais recebem pedidos de ajuda freqüentaram a escola $(r=0,266)$, têm mais tempo de moradia no local atual de residência $(r=0,257)$, apontaram uma visão negativa do envelhecimento $(r=0,204)$, não indicaram ser conformados com tudo $(r=-0,207)$ e têm mais preocupações financeiras $(r=0,225)$. Os respondentes que recebem ajuda de outras pessoas freqüentaram a escola $(r=0,300)$, são adultos $(r=-0,312)$, não referiram ser conformadas com tudo $(r=-0,238)$, quando precisam conversar contam com 
Tabela 2 - Correlações dos grupos de variáveis com faixa etária $(n=98)$

\begin{tabular}{|c|c|c|c|}
\hline Variáveis & 50 a 59 anos & 60 a 69 anos & 70 anos ou mais \\
\hline \multicolumn{4}{|l|}{ Variáveis D emográficas } \\
\hline Escolaridade & $0,242 *$ & & $-0,249 *$ \\
\hline Trabalho & $0,252 *$ & & $-0,226$ \\
\hline \multicolumn{4}{|l|}{ Variáveis R elacionadas às Tarefas E volutivas } \\
\hline A Iterações físicas são sinais do envelhecimento & $0,318^{* *}$ & & $-0,293 * *$ \\
\hline Enfermidades são sinais do envelhecimento & $-0,200 *$ & & \\
\hline Realização profissional & 0,234 & & \\
\hline Realização material & & & $-0,250 *$ \\
\hline Preocupação financeira & $0,275^{* *}$ & & \\
\hline Preocupação com a saúde & $-0,201 *$ & & \\
\hline Passam o dia trabalhando & $0,223^{*}$ & & \\
\hline \multicolumn{4}{|l|}{ Variáveis R elacionadas aos Papéis Sociais } \\
\hline Já moram no Distrito Federal & & & $0,217^{*}$ \\
\hline Tempo de moradia em Sobradinho & & & $-0,214 *$ \\
\hline Veio para a residência atual para ficar com a família & $-0,290 * *$ & & $0,344 * *$ \\
\hline Veio para a residência atual porque ganhou lote & $0,285^{* *}$ & & $-0,295^{* *}$ \\
\hline Tem hipertensão & $-0,221^{*}$ & & \\
\hline Número de pessoas da família & & $-0,298 * *$ & \\
\hline M ora com o cônjuge & $0,251 *$ & $-0,226^{*}$ & \\
\hline Participa de atividades sociais & $0,281^{* *}$ & 0,226 & \\
\hline Participa de atividades religiosas & $0,326 * *$ & 0,320 & \\
\hline Gosta de atividades domésticas & & & $0,269 * *$ \\
\hline É conformado com tudo & $-0,218 *$ & & $0,313^{* *}$ \\
\hline A juda outras pessoas & & & $-0,221^{*}$ \\
\hline Recebe ajuda de outras pessoas & $0,218 *$ & & $0,376^{* *}$ \\
\hline
\end{tabular}

Coeficiente de correlações de Pearson $* p>0,005 * * p>0,001$

a família $(r=-0,229)$ e também recebem pedidos de ajuda $(r=0,257)$.

Foram observadas também algumas diferenças entre os idosos-jovens (60 a 69 anos) e idosos-idosos (70 anos acima), conforme mostra a Tabela II: (a) os idosos-jovens possuem famílias menores $(r=-0,298)$, não moram com seus cônjuges $(r=-0,226)$ e participam de atividades sociais $(r$ $=0,226)$, principalmente as mulheres religiosas $(r=0,320)$; (b) os idosos-idosos não freqüentaram a escola $(r=-0,249)$, não estão trabalhando atualmente $(r=-0,226)$, moram há menos tempo no local da pesquisa $(r=-0,214)$, vieram de outros estados $(r=-0,217)$, moram com a família $(r=$ $0,344)$, gostam de atividades domésticas $(r=0,269)$ e são conformados com tudo $(r=0,313)$.

\section{Discussão}

\section{Tarefas evolutivas}

Os dados deste estudo demonstraram que o envelhecimento é visto como um evento de vida negativo associado a doenças, contrastando com expectativas sociais e valores culturais que priorizam beleza e produtividade. Neste sentido, Jacson (citado por Durkin, 1995) afirma que quando uma pessoa se aposenta diminui sua autoridade, seu papel econômico se torna menos claro, sua renda diminui; como esses critérios definem uma situação social, ocorre, consequentemente, uma perda de status.

O nível mais alto de escolaridade também contribuiu para uma visão negativa da velhice, sugerindo que a escola reforçou os estereótipos sociais da velhice que direcionam o comportamento pessoal e as escolhas pelo curso de vida (Durkin, 1995). A predominância da visão negativa ainda pode estar ligada à maneira como os próprios respondentes se vêem (Durkin, 1995) e às atitudes negativas que a sociedade tem em relação aos idosos. Segundo Neri (1991), essas atitudes podem ser reflexo dos sentimentos negativos em relação ao baixo status sócio-econômico, problemas de saúde e solidão, freqüentemente associados à velhice. Dessa forma, expectativas sociais e valores culturais influenciam na realização das tarefas evolutivas dos adultos e, no presente estudo, parecem contribuir para a manutenção de uma visão negativa da velhice .

Apesar das expectativas sociais tenderem a uniformizar as condições de vida dos idosos de uma mesma classe social, por meio da manutenção de estereótipos negativos, isto não significa que esses respondentes não possam alcançar um ajustamento satisfatório. Recorrendo a uma das proposições de Baltes (1991) para o envelhecimento bem sucedido, esses indivíduos possuem capacidades de reservas que, se ativadas, podem ajudar a responder aos estereótipos da velhice por processos de auto-regulação da personalidade 
que propiciem sensação de auto-estima positiva e de satisfação pessoal.

Ao se referirem à família, os respondentes idosos-idosos e idosos-jovens indicaram satisfação por terem constituído uma família e criado os filhos. Essas referências são indicativas da resolução do conflito geratividade x estagnação. Embora Erikson (1950) tenha apontado a geratividade como a tarefa evolutiva mais importante na meia idade, também sugeriu que, em princípio, estas tarefas estão presentes em todas as fases da vida (Baltes, 1998).

As preocupações manifestadas pelos respondentes confirmam que a família é a preocupação primeira, em todas as faixas etárias estudadas Observa-se a manifestação de geratividade quando das referências à profissão como a principal fonte de realização e à situação financeira como uma preocupação atual importante. Para os respondentes, a produção de bens e produtos pelo trabalho assegura a possibilidade de ajudar o outro, bem como o reconhecimento social. Essa idéia é reforçada pela afirmação de Neri (1991) de que "geração e criação de filhos, inserção no mercado de trabalho e na vida social, responsabilidade pela transmissão de modelos e valores às novas gerações" (p. 90) são importantes para que o adulto possa se reconhecer e ser reconhecido como maduro.

A forma como os respondentes encaram o cotidiano é influenciada, também, por valores culturais que ressaltam a importância da produtividade e por questões de gênero que estabelecem os papéis femininos e masculinos.

Apesar da expectativa de que o futuro seja bom, a maioria dos respondentes não planeja essa conquista, espera que ela aconteça. Lazaeta (1994) propõe que a maioria dos indivíduos enfrente a velhice com resignação, conformandose com tudo que lhes acontece e sentindo que nada podem fazer para mudar a maneira como vivem. Dessa forma, podese concluir que não há um nível adequado de mobilização, no sentido de utilizar estratégias de compensação e otimização para conquistar um desenvolvimento satisfatório.

Alguns respondentes demonstraram ansiedade em relação ao futuro, manifestando medo da morte, medo de adoecer e ficar dependentes, indicando uma falha na resolução do conflito entre a integridade do ego e o desespero, tal qual a proposição de Erikson (1950). Muito embora se destaque a importância da integridade do ego para redefinição da identidade e engajamento em novos papéis, de acordo com Neri (1991) a sociedade não valoriza o esforço que o indivíduo empreende para realizar esta tarefa. Este é um fator preocupante vez que, segundo Erikson (1950), a resolução do conflito integridade do ego versus desespero é de vital importância para o desenvolvimento da confiança em si próprio e da capacidade de assegurar confiança às gerações mais jovens, à medida que as gerações se revezam e se enriquecem.

Estas tarefas evolutivas indicam que os objetivos de vida selecionados pelos respondentes como os mais importantes apontam que o envelhecimento, enquanto processo de adaptação, é influenciado pelos recursos que esses indivíduos possuem, em termos de percepção das possibilidades de inserção social e condições de sobrevivência.

\section{Papéis Sociais}

Os achados do presente estudo corroboram estudos anteriores (Anzola-Perez, Wallace, Restrepo \& Colsher, 1993; Berquó, 1996; Veras, 1994): à medida que a idade aumenta, o nível de escolaridade diminui. Segundo Veras (1994), isto se deve ao fato de que no começo deste século a educação era restrita a uma elite social, sendo mais comum entre homens que entre as mulheres.

Os arranjos de moradia foram influenciados por estado civil, idade e gênero. Os dados indicam que os homens, independente da faixa etária, moram com esposas e filhos; as mulheres adultas moram com seus cônjuges e filhos; e as mulheres idosas-jovens e idosas-idosas moram com filhos, netos e genro/nora.

Estes dados também estão de acordo com os motivos de mudança para a atual moradia, pois os adultos moram há mais tempo no assentamento e abrigam os idosos, que anteriormente moravam em outros estados. Esses dados estão de acordo com estudos realizados por Sant'Anna (1997), que apresentam a mesma tendência.

Segundo Veras (1994), a maioria dos países latino-americanos vivencia uma migração generalizada para as grandes cidades. As pessoas saem do campo em busca de vida melhor. Neste estudo pôde-se observar que a situação financeira parece ter sido o principal motivo da mudança. Pôde-se notar, também, que o fato de morar na região geográfica à época da mudança para o assentamento, favoreceu as condições de vida dos respondentes em termos de saúde, trabalho, acesso à escola e rede de suporte social.

A maioria dos respondentes adultos e do sexo masculino está trabalhando, indicando que os idosos-jovens e idosos-idosos, em geral dependem financeiramente dos familiares. A ocupação que os respondentes deste estudo exercem ou exerceram se agrupam principalmente no ramo da prestação de serviços pessoais, revelando que muitos empregos são informais e sem carteira assinada. Em decorrência disso, um número irrelevante de respondentes, oito, está aposentado.

Em pesquisa realizada por Veras (1994) no Rio de Janeiro, as mulheres foram as que mais se queixaram de problemas de saúde. Esse dado, entretanto, não indica que as mulheres adoeçam mais que os homens. De modo geral, as mulheres têm mais consciência dos sintomas, melhor conhecimento das doenças e procuram mais os serviços de saúde (Garda \& Rezende, 1998, 22 de fevereiro).

Os problemas de saúde mais citados foram os circulatórios, principalmente a hipertensão. Dados do Ministério da Saúde (1995) apontam que as doenças do aparelho circulatório ocupam o primeiro lugar entre as causas de morte no país, sendo responsáveis por $37 \%$ das mortes de pessoas com mais de 50 anos.

Um grande número de respondentes deste estudo não desenvolve nenhuma atividade social. Os respondentes idosos-jovens participam mais de atividades sociais que os ido- 


\section{R. Silva e I. A. Günther}

sos-idosos. Essas atividades se restringem às atividades religiosas, desenvolvidas principalmente pelas mulheres mais idosas e pelas viúvas.

As atividades que os respondentes desempenham são definidas por questões de gênero, ou seja, as ocupações de homens e mulheres são influenciadas pelo que a cultura define como mais adequado e aceitável. Assim, as mulheres referem gostar mais das atividades domésticas, principalmente as viúvas, e os homens gostam mais de trabalhar fora de casa.

Em relação ao suporte social foi observada uma influência da variável idade na quantidade de respondentes que recebem ajuda e que oferecem ajuda a outras pessoas. $\mathrm{O}$ fato de que quanto maior a idade, menos respondentes recebem pedidos de ajuda de outras pessoas, sugere que a visão que a comunidade tem dos idosos está associada à improdutividade e passividade. Quem mais ajuda também é mais ajudado, portanto, a rede de suporte social dos adultos é maior. Constatou-se também que os respondentes que possuem uma rede de relações maiores também possuem uma escolaridade maior, recebendo mais pedidos de ajuda e sendo, também mais ajudados.

Os dados confirmaram, ainda, que os viúvos têm mais amigos. Estudos realizados por Pretowsky (1976) e Roberto e Scott (1984) corroboram o dado de que viúvos apresentam maior frequiência de interações com amigos do que os casados.

Observamos que todos os respondentes oferecem ou recebem diversos tipos de suporte social. Dentre eles, os mais citados foram: ajuda financeira ou material, auxílio nos serviços domésticos, ajuda afetiva ou espiritual, companhia e transporte. Lund (citado por Durkin, 1995), ressalta a importância desse suporte social para propiciar um contexto mais favorável para a solução de problemas.

Os respondentes informaram que ajudam mais aos amigos, vizinhos e familiares. De acordo com Ayéndez (1994), a dedicação a amigos e vizinhos é motivada por laços afetivos e obrigações. Segundo Goldstein (1995), esse suporte favorece o aumento do bem-estar subjetivo.

Segundo Durkin (1995), a família é o pivô da existência social do indivíduo, e o ajustamento social na velhice está estreitamente ligado ao envolvimento social com a família. Mais da metade dos sujeitos informaram contar com a família para conversar - em primeiro lugar com os filhos -, o que confirma resultados de outros estudos sobre suporte social na velhice (Baltes \& Silveberg, 1995).

Observamos que de maneira geral os respondentes, de todas as faixas etárias, se mostraram satisfeitos com seus relacionamentos. Assim sendo, podemos dizer que esses dados em relação ao suporte social indicam que os idosos não se isolam, mas continuam a manter uma rede de amigos, alguns mais restritos à família que outros, confirmando as proposições de Datan, Rodheaver \& Hughes, (1987).

A avaliação dos resultados suscitou algumas considerações que devem ser observadas em estudos futuros. A primeira delas se refere às interferências de terceiros que, durante as entrevistas, respondiam antes que os entrevistados falassem. Em muitas ocasiões os idosos não são reforçados sequer a dar informações, quanto mais a decidir o que querem, ou não querem, para suas vidas. Alguns respondentes chegaram a declarar que possuem dificuldade de expressar seus desejos à frente dos filhos, que querem tomar decisões sobre suas vidas. Isto confirma o despojamento social de que fala Bosi (1994) e a tolerância forçada a que são submetidos no convívio social.

\section{Considerações finais}

O grupo de respondentes deste estudo é heterogêneo e, apesar de a maioria informar que apresenta algum problema de saúde, não se observou comprometimento de autonomia, sendo os respondentes capazes de exercer atividades próprias à sua idade. Entretanto, poucos respondentes participam de atividades sociais, restringindo-se às atividades religiosas e às produtivas.

Além disso, o acesso aos serviços de saúde e a outros serviços de apoio que possam facilitar a vida dos idosos é restrito. Considerando que para compensar as perdas decorrentes da diminuição do potencial biológico é importante que o idoso tenha acesso a serviços de qualidade para favorecer um envelhecimento bem sucedido, faz-se necessário que políticas governamentais tornem possível essa assistência.

Considerando também que, segundo Baltes (1997), à medida que envelhece o indivíduo tem maior necessidade da cultura para compensar perdas e, principalmente, que a educação pode oferecer instrumentos para otimizar, compensar e estimular o desenvolvimento e a aquisição de novas habilidades e recursos, podemos dizer que a falta de escolarização traz grande prejuízo para o desenvolvimento dessas pessoas. A escolarização favorece a situação econômica e fornece recursos para que o indivíduo possa preparar-se melhor para envelhecer e compensar as perdas decorrentes do processo. É imprescindível que políticas de educação sejam implementadas para beneficiar os adultos que não tiveram acesso à escola e para evitar que outras pessoas fiquem na mesma situação, no futuro.

Ficou evidente que além das variáveis demográficas, as variáveis relacionadas à procedência e à moradia atual influenciam papéis sociais e tarefas evolutivas, por definirem condições de vida que favorecem ou limitam o acesso aos recursos necessários para um envelhecimento bem sucedido. No dizer de Neri (1993), a "promoção da boa qualidade de vida na idade madura excede os limites da responsabilidade pessoal e deve ser vista como um empreendimento de caráter sociocultural" (p.9). Se não forem promovidas modificações na estrutura social, dificilmente serão eliminados as dificuldades e os sofrimentos desse estrato da população.

Associado a tais fatores, Neri (1993) chama atenção para o fato de que a manutenção de uma sensação positiva da personalidade, a consideração de novas metas - quando as já estabelecidas não podem ser alcançadas -, a flexibilidade ante as condições de vida e o acesso a novas referências 
que permitam uma reorganização dos padrões pessoais e dos valores favorecem a manutenção da auto-regulação que também protege o indivíduo.

Podemos concluir que, para este grupo, envelhecer significa viver com dificuldades econômicas, doenças e sentimentos de desvalorização social. O conformismo conduz a uma falta de mobilização para lutar e conquistar melhores condições de vida. Apesar de todas as adversidades, essas pessoas encontram proteção e suporte no relacionamento com família, amigos, vizinhos, e por meio da crença religiosa. Além disso, os dados sugerem que a confiança em Deus e a segurança em relação à moradia mostraram-se positivas, possibilitando um aumento da satisfação de vida.

A partir do presente trabalho é possível delinear sugestões para o planejamento de políticas de atendimento a essa população, tais como: implantação de serviços de apoio e orientação voltados para o lazer, esporte, trabalho e suporte emocional, que oportunizem a convivência com pessoas de diversas faixas etárias; o desenvolvimento de campanhas de orientação sobre os problemas de saúde; treinamento e orientação para as equipes de atendimento aos serviços de saúde para que identifiquem idosos em situações de riscos físicos, psicológicos e sociais e possibilitem uma atuação preventiva e curativa; implementação de serviços de apoio aos idosos, com acesso a consultas, exames e medicamentos.

Finalmente, espera-se que este estudo, somado a outros, contribua para que os indivíduos possam ter condições de envelhecer bem no futuro, mantendo envolvimento com pessoas e eventos, tendo oportunidade de se manterem ativos e de se sentirem bem em relação a si mesmos. Afinal, o futuro dos idosos dependerá em grande parte da habilidade para gerar e empregar cultura e tecnologias com o objetivo de alcançar níveis de funcionamento que compensem as perdas.

\section{Referências}

Anzola-Perez, E. (1985). El envejecimiento en América Latina y el Caribe. Em Organização Panamericana de la Salud. Hacia el bienestar de los ancianos (pp. 9-24). Washington, D.C.: Organização Panamericana para a Saúde.

Anzola-Perez, E., Wallace, R., Restrepo, H., \& Colsher, P. (1993). Analisis comparativo del envejecimiento en Brasil, Colombia, El Salvador, Jamaica y Venezuela. Cuaderno Técnico N. ${ }^{\circ}$ 38. Washington: OPAS.

Ayéndez, M.S. (1994). El apoyo social informal. Em Elías AnzolaPeréz \& cols. (Org.). La atención de los ancianos: um desafio para los años noventa (pp. 360-368). Washington, D.C.: Organização Panamericana para a Saúde.

Baltes, P.B. (1987). Theoretical propositions of life-span developmental psychology: On the dynamics between growth and decline. Developmental Psychology, 23, 611-696.

Baltes, P.B. (1991). The many faces of human ageing: toward a psychological culture of old age. Psychological Medicine, 21, 837-854.
Baltes, P.B. (1995). Prefácio. Em A.L. Neri, (Org.). Psicologia do Envelhecimento: Temas selecionados na perspectiva de curso de vida (pp. 9-12). Campinas: Papirus.

Baltes, P.B. (1997). On the incomplete architecture of humam ontogeny: selection, optimization, and compensation as foundation of developmental theory. American Psychologist, 52(4), 366-380.

Baltes, P.B. (1998). Life-span theory in developmental psychology. Em W. Damon \& R.M. Lerner (Orgs.). Handbook of Child Psychology. 5 ${ }^{\text {a }}$ ed. Vol. 01. Theoretical Models of Human Development (pp. 1029-1144). Texas: John Wiley \& Sons.

Baltes, P.B., Reese, H.W. \& Lipsitt, L.P. (1980). Life-span developmental psychology. Em M.R. Rosenzweig \& L.M. Porter (Orgs.). Annual Review of Psychology, 31, 65-110. Palo Alto, CA: Annual Reviews.

Baltes, M.M. \& Silveberg, S. (1995). A dinâmica dependênciaautonomia no curso de vida. Em A.L. Neri (Org.). Psicologia do Envelhecimento: Temas selecionados na perspectiva de curso de vida (pp. 73-110). Campinas: Papirus.

Berquó, E. (1996, julho). Algumas considerações sobre o envelhecimento da população no Brasil. Trabalho apresentado no Seminário Internacional Sobre o Envelhecimento Populacional: uma agenda para o fim do século. Brasília, Brasil.

Bosi, E. (1994). Memória e sociedade: lembranças de velhos. 3. ${ }^{2}$ ed. São Paulo: Companhia das letras.

Datan, N., Rodeheaver, D., \& Hughes, F. (1987). Adult development and aging. Annual Review of Psychology, 38, 153-180.

Durkin, K. (1995). Developmental social psychology. Cambridge: Blackwell

Erikson, E. (1950). Childhood and Society. New York: Norton.

Fitch, V. (1985). The psychological tasks of old age. Narope Institute Journal of Psychology, 3, 90-106.

Garda, C. \& Rezende, H. (1998, 22 de fevereiro). A descoberta do sexo frágil. Correio Brasiliense. Caderno Brasil. p. 13.

Goldstein, L.L.L. (1995). Stress e coping na vida adulta e velhice. Em A. L. Neri (Org.). Psicologia do Envelhecimento: Temas selecionados na perspectiva de curso de vida (pp. 145158). Campinas: Papirus.

Haddad, E.G.M. (1993). O direito à velhice: os aposentados e a previdência social. São Paulo: Cortez.

Havighurst, R.J. (1953). Human Development and Education. Nova York: David McKay Company.

Kahn, R.L. \& Antonucci, T.C. (1979). Convoys over the life course: Attachement, roles and support. Manuscrito não publicado. Institute for Social Research. University of Michigan, Michigan.

Lazaeta, C.B. (1994). Aspectos sociales del envejecimento. Em Elías Anzola-Pérez, David Galinsky, Fernando Morales Martínez, Aquiles R. Salas \& Melba Sanches Ayéndez (Orgs.). La atención de los ancianos: un desafio para los años noventa (pp. 57-66) Washington, D.C.: Organização Panamericana para a Saúde.

Ministério da Saúde (1995). Sistema de Informações sobre mortalidade. Brasília: Sistema Único de Saúde.

Neri, A.L. (1991). Envelhecer num país de jovens: significados de velho e velhice segundo brasileiros não idosos. Campinas, SP: Editora da Unicamp. 
Neri, A.L. (1993). Qualidade de vida no adulto maduro: Interpretações teóricas e evidência de pesquisa. Em A.L. Neri (Org.). Qualidade de vida e idade madura (pp. 9-55). Campinas: Papirus.

Neri, A.L. (Org.) (1995). Psicologia do Envelhecimento: Temas selecionados na perspectiva de curso de vida. Campinas: Papirus.

Petrowsky, M. (1976). Marital Status, Sex, and Social Network of the Elderly. Journal of Marriage and the Family, 38, 479-756.

Neugarten, B.L. \& Weinstein, K.K. (1964). The changing American grandparent. Journal of Marriage and the Family. 26, 199206.
Roberto, K. \& Scott, J. (1984). Friendship patterns among older women. International Journal of Aging and Human Development, 19, 1-10.

Sant'Anna, M.J.G. (1997). UnATI, a velhice que se aprende na escola: um perfil de seus usuários. Em R.P. Veras (Org.). Terceira Idade: desafios para o terceiro milênio. (pp. 75-102). Rio de Janeiro: Relumé-Dumará: UnATI/UERJ.

Stevens-Long, J. (1979). Adult Life: developmental processes. Palo Alto, CA: Mayfield.

Veras, R.P. (1994). País jovem com cabelos brancos. Rio de Janeiro: Relume Dumará.

\section{INTERESSADO EM AGILIZAR A PUBLICAÇÃO DE SEU ARTIGO?}

\section{Informações e dicas para os autores sobre aspectos operacionais}

\section{O manuscrito é reencaminhado pelo autor} em versão reformulada

A produção gráfica do trabalho é executada através de editoração eletrônica, daí a exigência do exemplar em disquete, além de três exemplares em papel da versão reformulada. Quando a versão reformulada é aceita e são poucos os reparos, as correções necessárias são feitas na secretaria da revista. Com o disquete disponível o processamento pode ser imediatamente iniciado. Na falta de disquete não é possível o processamento de correções nem a preparação do manuscrito para editoração. Em suma, atraso para entrar no prelo.

\section{Informações e dicas para os autores com artigos no prelo}

\section{O manuscrito é encaminhado para editoração}

No caso de o manuscrito ser aceito para publicação, é esperada a participação do autor no processo de preparação do artigo na fase de editoração. A primeira prova do artigo, editada a partir da versão em disquete, é enviada para exame ao(s) autor(es). O prazo para devolução é de 48 horas. A obediência ao prazo permite a manutenção da composição prevista para o volume/número da revista. $\mathrm{O}$ atraso no envio da prova examinada pode implicar em mudanças na composição de um número no prelo. E pode resultar em atraso na edição final. 